PETER RAILTON

\title{
PRÉCIS OF FACTS, VALUES, AND NORMS
}

Moral thought and feeling are integral to how we see ourselves, how we live, and how we understand one another. Yet morality itself remains in many ways hard to understand. We speak of it as if it were a domain of knowledge, but what sort of knowledge could this be, and how would we acquire or test it? We appeal to it as if it afforded an objective standard for criticism and justification, rising above the level of personal aims or local custom, but what ground can we point to if asked to back this up? And we see it as having significant action-guiding force or normative authority, yet find it no easy matter to explain what this means, much less what would account for it. Small wonder Kant took seriously the worry that moral notions might covertly be based in "mere high-flown fantasy."

The essays collected in Facts, Values, and Norms attempt to make morality a bit more understandable, and thereby a bit less vulnerable to skepticism. They do so within what strives to be a coherent framework for meta-ethics and normative ethics, a form of naturalistic realism that treats moral inquiry as continuous in method with empirical science. Many philosophers believe, I know, that such a view is wrong-headed from the outset. Whatever morality is, they argue, it is not an empirical theory of anything - morality's character and methods belong to practical rather than theoretical reason. I believe that such criticisms run together things we do with moral language - express commitment, claim authority, guide action, exert sanctions - with what moral claims literally say such that moral discourse could sustain such uses. 
Part I of this collection is explicitly meta-ethical. Moral judgments, on my view, are not a species of practical endorsement, but cognitive claims with distinctive purport objectivity, impartiality, benevolence, generality, etc. - and ordinary truth conditions. Moral concepts are not reducible to non-moral concepts, but moral properties can be explicated in non-moral terms via largely functional "job descriptions" of their putative role in thought, self-regulation, and social practice. Intrinsic value can be explicated in terms of informed higher-order desires - hence, the slogan, "value as objectified subjectivity" (applicable, I argue, in ethics and aesthetics alike). Moral goodness and rightness can in turn be explained in terms of intrinsic value and the concept of a moral point of view.

The resulting view is a full-blooded factualist realism. Moral properties and moral truth need not be understood in the pleonastic, "lite" manner common to contemporary expressivists and quasi-realists. Rather, moral properties are seen as capable of playing explanatory roles in their own right, and therefore suited for experiential learning and semantic access. Existence internalism about intrinsic good is combined with judgment externalism about moral rightness. Thus, I hold that what is intrinsically good for a person must be something that could matter to her for its own sake. But I also hold, with Hume, that our moral concepts and practices are compatible with the possibility that someone might make genuine moral judgments while lacking corresponding motivation. I am not a judgment externalist faut de mieux - instead, I believe that externalism about moral judgment is part of the most plausible explanation of how and why problems of moral motivation arise in actual moral practice. Moreover, like some contemporary intuitionists, I do not find it plausible to appeal to the "internal" motivational force of moral judgments to explain their distinctive normative authority.

Part II of the collection turns to questions of normative ethics. Here I defend what I take to be the guiding consequentialist idea, namely, that morality can be given a foundation in facts about how the ways we live can make lives 
better or worse, against a number of criticisms lodged against orthodox utilitarianism. Success in this project requires consequentialists to be alive to the diversity of intrinsic goods, and to the variety of ways in which value is realized in lives. They must resist the dialectical pressure to translate their view into a narrow, seemingly implausible, deontology or decision-procedure. I coin the awkward term 'valoric consequentialism' for the broad, value-oriented approach to normative ethics I would urge as a replacement for act and rule utilitarianism. The advantage of a value-orientation is nowhere more apparent than in moral dilemmas. I argue that many dilemmas gain their poignancy not from an irresolvable clash of duties - one choice may be clearly right, or either choice is clearly permitted - but from our inability to affirm or express all the values we hold dear, so that, whatever we do, something that matters very much must be lost.

In Part III of the collection, I venture into the maze of issues that has become known as "the problem of normativity". On the one hand, morality has non-hypothetical authority, so that moral judgments can apply even to those who lack any contingent motivation to follow them; on the other hand, no one has succeeded in explaining this authority by showing that failure to be responsive to moral considerations is necessarily a form of practical irrationality. Progress in treating the normative authority of moral discourse depends, in my view, not on establishing an inescapable conceptual or rational necessity, but on understanding the free aspiration of our moral practices. Stevenson's identification of the "magnetism" of moral discourse is quite apt - we should be looking for an attractive pull rather than an unavoidable push. Remarkably, humans have a long history of aspiring to think, speak, and act with the authority of morality, and have thus attempted to hold their judgments and conduct accountable to standards that are objective, general, and grounded in the facts. Why? Well, for one thing, we seek legitimacy and respect in our own eyes and the eyes of others, and such standards can be defended to any unbiased person of good will and good sense. 'Morally right', in our mouths, 
is able to carry the normative purport to which we aspire if we form a community of judgment that disciplines its use of 'morally right' by the relevant objective criteria and standards of evidence. We recognize that this means we will sometimes find ourselves in the wrong - a standard that would pat us on the back for everything we do could never command our respect, and so meeting it could be no source of self-respect. Of course, all this might be a myth we tell ourselves, a shimmering self-congratulatory illusion. In a final essay, I argue that we can make a case against dismissing our aspirations as so much self-serving ideology, but only if we philosophers roll up our sleeves and develop an empirically respectable vindicatory explanation of our moral thought and practice. Hume, I believe, thought he had done this in the Treatise when he wrote somewhat hyperbolically in its Conclusion:

It requires but very little knowledge of human affairs to perceive, that a sense of morals is a principle inherent in the soul, and one of the most powerful that enters into the composition. But this sense must certainly acquire new force, when reflecting on itself, it approves of those principles from whence it is deriv'd, and finds nothing but what is great and good in its rise and origin. [III.3.vi]

Department of Philosophy

University of Michigan

435 South State Street,

Ann Arbor, MI, 48109-1003

USA

E-mail: prailton@umich.edu 